\title{
Rancangan Acak Lengkap Dan Rancangan Acak Kelompok Pada pH Gelatin Kulit Domba Dengan Pretreatment Larutan NaOH
}

\author{
Muhamad Hasdar*1, Wadli ${ }^{2}$, dan Delia Meilani ${ }^{3}$ \\ ${ }^{1,2,3}$ Program Studi Ilmu dan Teknologi Pangan, Universitas Muhadi Setiabudi, Brebes, Indonesia \\ e-mail:*hasdarmuhammad@umus.ac.id
}

\begin{abstract}
Abstrak
Pada penelitian ini bertujuan untuk mengetahui perbedaan hasil dan kesimpulan data yang diolah menggunakan rancangan acak lengkap dan rancangan acak kelompok dari data $\mathrm{pH}$ gelatin kulit domba yang dilakukan pretreatment larutan NaOH. Metode yang digunakan pada penelitian ini yaitu analisis deskriptif berdasarkan hasil ANOVA dari Rancangan Acak Lengkap $(R A L)$ dan Rancangan Acak Kelompok (RAK) dari data hasil pengukuran pH gelatin kulit domba. RAK menghasilkan galat dan koefisien keragaman yang lebih kecil, namun tidak menghasilkan nilai yang signifikan untuk keragaman kelompok. Uji lanjut yang cocok yaitu uji tukey.
\end{abstract}

Kata kunci : RAK, RAL, Gelatin, Domba

\begin{abstract}
This study aims to know the difference in results and the conclusion of the processed data using a complete random design and a random design of the group from the $\mathrm{pH}$ data of the sheepskin gelatin done pretreatment solution $\mathrm{NaOH}$. The method used in this research is a descriptive analysis based on the results of ANOVA of Complately Randomized Design (CRD) and Randomized Blok Design (RBD) of the data of the pH measurement of the sheepskin gelatin. Randomized block design generates errors and smaller coefficient of diversity, does not produce significant value for the diversity of groups. A suitable advanced test is the tukey test.
\end{abstract}

Keywords : $C R D, R B D$, Gelatin, Sheep

\section{PENDAHULUAN}

Pada umumnya rancangan percobaan merupakan suatu rangkaian kegiatan bertahap dimana setiap tahap dalam rangkaian benar-benar terdefenisikan dan dilakukan untuk menemukan jawaban tentang permasalahan yang sedang diteliti melalui suatu pengujian hipotesis [1]. Secara sederhana rancangan percobaan ditujukan untuk mengamati pengaruh $X$ terhadap $Y$ atau mengamati pengaruh perlakuan (X) terhadap hasil pengamatan (Y). Rancangan percobaan diharapkan menghasilkan sesitifitas percobaan yaitu rancangan yang memiliki kesalahan percobaan yang paling kecil sehingga perbedaan-perbedaan setiap perlakuan dapat dideteksi dengan benar. Pada prinsipnya penggunaan rancangan percobaan untuk mendapatkan mendapatkan informasi yang maksimum dan dapat menghasilkan kesimpulan yang tepat dengan biaya seminim mungkin serperti waktu, tenaga, dan biaya.

Analisis variansi atau analisis sidik ragam adalah suatu metode untuk menguraikan keragaman total data menjadi komponen-komponen yang mengukur berbagai sumber keragaman. Analisis variansi dapat digunakan untuk data observasional (penelitian) maupun data experimental (percobaan). Dalam suatu percobaan akan didapatkan nilai-nilai hasil pengamatan. Nilai-nilai hasil pengamatan tersebut umumnya dinyatakan dalam suatu model matematika yang disebut model linier [2]. Analisis Keragaman (ANOVA) merupakan proses pembagian total keragaman pengamatan percobaan kedalam porsi sumber-sumber keragaman yang ada. Dari ANOVA kita dapat menduga keragaman populasi perlakuan dengan suatu kuantiti yang disebut. Galat Percobaan (Experimental Error) yang menunjukkan besarnya keragaman yang diakibatkan 
oleh semua sumber keragaman yang tak terhitung. Hal ini dapat terjadi karena berbagai hal, seperti: 1) Perbedaan-perbedaan sifat alami, 2). Kurang keseragaman dalam pengulangan percobaan, dan 3) unsur-unsur lainnya [3].

Pada percobaan pengolahan kulit domba menjadi gelatin diperlukan metode percobaan yang tepat dalam pengambilan kesimpulan dengan membandingkan perlakuan yang berbeda untuk mendapatkan perlakuan yang terbaik atau formula yang tepat dalam pengolahan kulit domba menjadi gelatin. Salah satu parameter untuk mengukur kualitas gelatin adalah $\mathrm{pH}$. Tinggi rendahnya $\mathrm{pH}$ gelatin domba akan berpengaruh pada kualitas atau jenis produk lanjutannya [4].

Pada penelitian ini bertujuan untuk mengetahui perbedaan hasil dan kesimpulan data yang diolah menggunakan rancangan acak lengkap dan rancangan acak kelompok dari data $\mathrm{pH}$ gelatin kulit domba yang dilakukan pretreatment larutan $\mathrm{NaOH}$.

\section{METODE PENELITIAN}

Metode yang digunakan pada penelitian ini yaitu analisis deskriptif berdasarkan hasil ANOVA dari Rancangan Acak Lengkap (RAL) dan Rancangan Acak Kelompok (RAK) dari data hasil pengukuran $\mathrm{pH}$ gelatin kulit domba yang telah dilakukan pretreatment $\mathrm{NaOH}$. Langkahlangkah dari penelitian ini yaitu 1) pengujian RAL dan RAK, 2) penarikan hipotesis, 3) Koefisien Keragaman (KK), 4) penarikan kesimpulan RAL dan RAK, dan Pembandingan hasil pengujian RAL dan RAK, dan keragaman menurut RAL dan efisiensi RAK terhadap RAL [5] [6].

\section{Rancangan Acak Lengkap}

Pada rancangan acak lengkap memiliki model linear yaitu

$\mathrm{Y}_{\mathrm{ij}}=\mu_{\mathrm{i}}+\tau_{\mathrm{i}}+\varepsilon_{\mathrm{ij}}$ atau $\mathrm{Y}_{\mathrm{ij}}=\mu_{\mathrm{i}}+\varepsilon_{\mathrm{ij}}$

dimana :

$\mathrm{i} \quad=1,2, \ldots, \mathrm{t}$

$\mathrm{j} \quad=1,2, \ldots, \mathrm{r}$

$\mathrm{Y}_{\mathrm{ij}} \quad=$ pengamatan pada perlakuan ke-i dan ulangan ke-j

$\mu \quad=$ rataan umum

$\tau_{\mathrm{i}} \quad=$ pengaruh perlakuan ke- $\mathrm{i}$

$\varepsilon_{\mathrm{ij}} \quad=$ Pengaruh acak pada perlakuan ke-i dan ulangan ke-j

Tabel 1. Daftar Analisis of Variance untuk Rancangan Acak Lengkap

\begin{tabular}{|c|c|c|c|c|c|}
\hline \multirow{2}{*}{$\begin{array}{c}\text { Sumber } \\
\text { Keragaman }\end{array}$} & \multirow{2}{*}{$\begin{array}{c}\text { Derajat } \\
\text { Bebas }\end{array}$} & \multirow{2}{*}{$\begin{array}{l}\text { Jumlah } \\
\text { Kuadrat }\end{array}$} & \multirow{2}{*}{$\begin{array}{c}\text { Kuadrat } \\
\text { Tengah }\end{array}$} & \multirow[t]{2}{*}{$\mathbf{F}_{\text {Hitung }}$} & $F_{\text {tabel }}$ \\
\hline & & & & & $5 \%$ \\
\hline $\begin{array}{c}\text { Perlakuan } \\
\text { Galat }\end{array}$ & $\begin{array}{c}\mathrm{t}-1=\mathrm{V}_{1} \\
(\mathrm{rt}-1)-(\mathrm{t}-1)=\mathrm{V}_{2}\end{array}$ & $\begin{array}{l}\text { JKP } \\
\text { JKG }\end{array}$ & $\begin{array}{l}\mathrm{JKP} / \mathrm{V}_{1} \\
\mathrm{JKG} / \mathrm{V}_{2}\end{array}$ & KTP/KTG* & $\mathrm{F}\left(\mathrm{V}_{1}, \mathrm{~V}_{2}\right)$ \\
\hline Total & $\mathrm{rt}-1$ & JKT & & & \\
\hline
\end{tabular}

Hipotesis yang diuji yaitu :

$\mathrm{H}_{0}: \tau_{\mathrm{i}}=0$ (tidak apa pengaruh perlakuan terhadap $\mathrm{pH}$ gelatin kulit domba)

$\mathrm{H}_{1}: \tau_{\mathrm{i}} \neq 0$ (terdapat pengaruh perlakuan terhadap $\mathrm{pH}$ gelatin kulit domba)

Taraf pengujian yaitu $\alpha=0,05$ dan $\alpha=0,01$

Kriteria Uji: Tolak $\mathrm{H}_{0}$ jika nilai F-hitung $>$ F-tabel $(\alpha: 0,05)$ dan $(\alpha: 0,05)$ atau sig. $<\alpha$

\section{Rancangan Acak Kelompok}

Model linear dari Rancangan Acak Kelompok (RAL) yaitu:

$\mathrm{Yij}=\mu+\tau_{\mathrm{i}}+\beta \mathrm{j}+\varepsilon_{\mathrm{ij}}$ 
dimana :

$\mathrm{i} \quad=1,2, \ldots, \mathrm{t}$

$\mathrm{j} \quad=1,2, \ldots, \mathrm{r}$

$\mathrm{Y}_{\mathrm{ij}} \quad=$ Pengamatan pada perlakuan ke-i dan ulangan ke- $\mathrm{j}$

$\mu \quad=$ Rataan umum

$\tau_{\mathrm{i}} \quad=$ Pengaruh perlakuan ke-i

$\beta \mathrm{j}=$ Pengaruh kelompok ke- $\mathrm{j}$

$\varepsilon_{\mathrm{ij}} \quad=$ Pengaruh acak pada perlakuan ke-i dan ulangan ke-j

Tabel 2. Daftar Analisis of Variance untuk Rancangan Acak Kelompok

\begin{tabular}{|c|c|c|c|c|c|}
\hline \multirow{2}{*}{$\begin{array}{c}\text { Sumber } \\
\text { Keragaman }\end{array}$} & \multirow{2}{*}{$\begin{array}{c}\text { Derajat } \\
\text { Bebas }\end{array}$} & \multirow{2}{*}{$\begin{array}{c}\text { Jumlah } \\
\text { Kuadrat }\end{array}$} & \multirow{2}{*}{$\begin{array}{c}\text { Kuadrat } \\
\text { Tengah } \\
\end{array}$} & \multirow[t]{2}{*}{$\mathbf{F}_{\text {Hitung }}$} & $\mathbf{F}_{\text {tabel }}$ \\
\hline & & & & & $5 \%$ \\
\hline Kelompok & $\mathrm{k}-1=\mathrm{V}_{1}$ & JKK & $\overline{J K K / V_{1}}$ & KTK/KTG* & $F\left(V_{1}, V_{3}\right)$ \\
\hline $\begin{array}{l}\text { Perlakuan } \\
\text { Galat }\end{array}$ & $\begin{array}{c}\mathrm{t}-1=\mathrm{V}_{2} \\
(\mathrm{k}-1)(\mathrm{t}-1)=\mathrm{V}_{3}\end{array}$ & $\begin{array}{l}\text { JKP } \\
\text { JKG }\end{array}$ & $\begin{array}{l}\mathrm{JKP} / \mathrm{V}_{2} \\
\mathrm{JKG} / \mathrm{V}_{3}\end{array}$ & KTH/KTG* & $F\left(V_{2}, V_{3}\right)$ \\
\hline Total & $\mathrm{rt}-1$ & JKT & & & \\
\hline
\end{tabular}

Hipotesis yang diuji yaitu :

$\mathrm{H}_{0}: \tau_{\mathrm{i}}=0$ (tidak apa pengaruh perlakuan terhadap $\mathrm{pH}$ gelatin kulit domba)

$\mathrm{H}_{1}: \tau_{\mathrm{i}} \neq 0$ (terdapat pengaruh perlakuan terhadap $\mathrm{pH}$ gelatin kulit domba)

Taraf pengujian yaitu $\alpha=0,05$ dan $\alpha=0,01$

Kriteria Uji: Tolak $\mathrm{H}_{0}$ jika nilai $\mathrm{F}_{\text {-hitung }}>\mathrm{F}_{\text {-tabel }}(\alpha: 0,05)$ dan $(\alpha: 0,01)$ atau sig. $<\alpha$

\section{Koefisien keragaman}

Koefisien keragaman (KK) dihitung berdasarkan rumus sebagau berikut :

$\mathrm{KK}=\frac{\sqrt{\mathrm{KTG}}}{\overline{\mathrm{y}}} \times 100 \%$

dimana :

KTG = Kuadrat tengah galat

$\overline{\mathrm{y}} \quad=$ Rata-rata umum percobaan

Efisiensi RAK terhadap RAL

Untuk mengetahui efisensi RAK terhadap RAL dapat dihitung dengan menggunakan rumus :

Efisiensi RAK terhadap RAL $=\frac{\text { KTG RAL }}{\text { KTG RAK }}$

\section{HASIL DAN PEMBAHASAN}

\section{Rancangan Acak Lengkap}

Rancangan Acak Lengkap merupakan salah rancangan pada suatu lokasi yang homogen. Rancangan ini dikatakan acak karena pada setiap satuan percobaan mempunyai peluang yang sama untuk mendapatkan perlakuan sedangkan dikatakan lengkap karena seluruh perlakuan y ang dirancang dalam percobaan tersebut digunakan [2]. Sumber keragaman yang diamati pada rancangan ini hanya perlakuan dan galat. Kelebihan rancangan acak lengkap yaitu fleksibel, mudah dianalisis, dan derajat bebas estimasi maksimum terdapat pada error. Data hasil pengukuran $\mathrm{pH}$ gelatin kulit domba dimasukan dalam tabel pengelompokan berdasarkan pola RAL seperti tabel 3 dibawah ini. 
Tabel 3. Pengelompokan data berdasarkan pola Rancangan Acak Lengkap

\begin{tabular}{ccccccc}
\hline \multirow{2}{*}{ Perlakuan Larutan $\mathrm{NaOH}$} & \multicolumn{9}{c}{ Ulangan } & \multirow{2}{*}{ Jumlah } & Rerata \\
\cline { 2 - 6 } & I & II & III & IV & & \\
\hline 0,5 & 5.37 & 5.39 & 5.36 & 5.38 & 21.50 & 5.375 \\
1 & 5.29 & 5.33 & 5.31 & 5.28 & 21.21 & 5.303 \\
1,5 & 5.16 & 5.21 & 5.19 & 5.23 & 20.79 & 5.198 \\
2 & 5.02 & 5.14 & 5.09 & 5.13 & 20.38 & 5.095 \\
\hline Jumlah & 20.84 & 21.07 & 20.95 & 21.02 & 83.88 & 5.243 \\
\hline
\end{tabular}

Data yang telah didapatkan kemudian dihitung untuk mendapatkan derajat bebas, Jumlah Kuadrat, Kuadrat Tengah, dan $\mathrm{F}_{\text {hitung }}$ berdasarkan analisis ragam dengan rancangan acak lengkap. Hasil pengolahan data tersebut disajikan pada tabel 4 sebagai berikut.

Tabel 4. Analisis sidik ragam dengan Rancangan Acak Lengkap

\begin{tabular}{ccccccc}
\hline Sidik & $\begin{array}{c}\text { Derajat } \\
\text { Kebas }\end{array}$ & $\begin{array}{c}\text { Jumlah } \\
\text { Kuadrat }\end{array}$ & $\begin{array}{c}\text { Kuadrat } \\
\text { Tengah }\end{array}$ & $\mathrm{F}_{\text {hitung }}$ & \multicolumn{2}{c}{$\mathrm{F}_{\text {tabel }}$} \\
\hline $\begin{array}{c}\text { Perlakuan } \\
\text { NaOH }\end{array}$ & 3 & 0.1798 & 0.0599 & $57.485^{* * *}$ & 3.41 & 5.74 \\
Galat & 13 & 0.0135 & 0.0010 & & & \\
\hline Total & 16 & 0.1933 & & & & \\
\hline Keterangan $: * *$ & sangat nyata & & & & &
\end{tabular}

Berdasarkan hasil tabel 4. diketahui bahwa perlakuan $\mathrm{NaOH}$ memberikan pengaruh yang sangat nyata atau hipotesis $\mathrm{H}_{0}$ ditolak dan hipotesis $\mathrm{H}_{1}$ diterima, hal ini dilihat dari hasil $\mathrm{F}_{\text {hitung }}>$ $\mathrm{F}_{\text {tabel }}(\alpha: 0,05)$ dan $(\alpha: 0,01)$. Sehingga dapat disimpilkan bahwa perlakuan $\mathrm{NaOH}$ sangat mempengaruhi kualitas pH gelatin kulit domba, dan berarti ada pula salah satu perlakuan larutan $\mathrm{NaOH}$ yang pengaruhnya sangat menonjol jika dibandingkan dengan perlakuan larutan $\mathrm{NaOH}$ yang lain. berikut :

Derajat kejituan dapat dilihat dari hasil koefisien keragaman (KK) dari RAL sebagai

$$
\begin{aligned}
\mathrm{KK} & =\frac{\sqrt{\mathrm{KTG}}}{\overline{\mathrm{y}}} \times 100 \% \\
\mathrm{KK} & =\frac{\sqrt{0.0010}}{5.243} \times 100 \% \\
\mathrm{KK} & =0,62 \%
\end{aligned}
$$

Percobaan dengan perlakuan konsentrasi larutan $\mathrm{NaOH}$ mempunyai derajat kejituan dan keandalan yang kecil, dimana nilai KK berdasarkan RAL adalah 0,62\%. Sehingga untuk melakukan pengujian lanjutan cukup dilakukan dengan uji BNJ (Beda Nyata Jujur). Jika KK kecil (kurang dari 5\% pada kondisi homogen) maka uji lanjut yang tepat untuk dipakai adalah uji BNJ [7].

\section{Rancangan Acak Kelompok}

Rancangan ini biasanya digunakan pada dilingkungan heterogen, sehingga dibutuhkan pengelompokkan unit-unit percobaan untuk membuat lingkungan sehomogen mungkin. Tujuan utama dari pengelompokan adalah untuk membuat keragaman satuan-satuan percobaan [8]. Data 
hasil pengukuran $\mathrm{pH}$ gelatin kulit domba dimasukan dalam tabel pengelompokan berdasarkan pola RAK seperti pada tabel 5 dibawah ini.

Tabel 5. Pengelompokan data berdasarkan pola rancangan acak kelompok

\begin{tabular}{ccccccc}
\hline \multirow{2}{*}{ Perlakuan Larutan NaOH } & \multicolumn{9}{c}{ Kelompok } & \multirow{2}{*}{ Jumlah } & Rerata \\
\cline { 2 - 5 } & I & II & III & IV & & \\
\hline 0,5 & 5.37 & 5.39 & 5.36 & 5.38 & 21.50 & 5.375 \\
1 & 5.29 & 5.33 & 5.31 & 5.28 & 21.21 & 5.303 \\
1,5 & 5.16 & 5.21 & 5.19 & 5.23 & 20.79 & 5.198 \\
2 & 5.02 & 5.14 & 5.09 & 5.13 & 20.38 & 5.095 \\
\hline Jumlah & 20.84 & 21.07 & 20.95 & 21.02 & 83.88 & 5.243 \\
\hline
\end{tabular}

Data yang telah didapatkan kemudian dihitung untuk mendapatkan derajat bebas, Jumlah Kuadrat, Kuadrat Tengah, dan $F_{\text {hitung }}$ berdasarkan analisis ragam dengan rancangan acak kelompok. Hasil pengolahan data tersebut disajikan pada tabel 6 sebagai berikut.

Tabel 6. Analisis sidik ragam dengan rancangan acak kelompok

\begin{tabular}{ccccccc}
\hline \multirow{2}{*}{ Sidik Keragaman } & \multirow{2}{*}{ Derajat Bebas } & \multirow{2}{*}{ Jumlah Kuadrat } & \multirow{2}{*}{ Kuadrat Tengah } & \multirow{2}{*}{$\mathrm{F}_{\text {hitung }}$} & \multicolumn{2}{c}{$\mathrm{F}_{\text {Tabel }}$} \\
\cline { 6 - 7 } & & & & $5 \%$ & $1 \%$ \\
\hline Kelompok & 3 & 0.0075 & 0.0025 & $3.6639^{\text {ns }}$ & 3.86 & 6.99 \\
Perlakuan $\mathrm{NaOH}$ & 3 & 0.1798 & 0.0599 & $88.4016^{* *}$ & 3.86 & 6.99 \\
Galat & 9 & 0.0061 & 0.0007 & & & \\
\hline Total & 15 & 0.1933 & & & & \\
\hline Keterangan $: * *$ & sangat nyata & ${ }^{n \text { ns }}=$ tidak signifikan & & & &
\end{tabular}

Berdasarkan hasil tabel 6. diketahui bahwa perlakuan $\mathrm{NaOH}$ memberikan pengaruh yang sangat nyata atau hipotesis $\mathrm{H}_{0}$ ditolak dan hipotesis $\mathrm{H}_{1}$ diterima, hal ini dilihat dari hasil $\mathrm{F}_{\text {hitung }}>$ $\mathrm{F}_{\text {tabel }}(\alpha: 0,05)$ dan $(\alpha: 0,01)$. Sehingga dapat disimpilkan bahwa perlakuan $\mathrm{NaOH}$ sangat mempengaruhi kualitas $\mathrm{pH}$ gelatin kulit domba, dan berarti ada pula salah satu perlakuan larutan $\mathrm{NaOH}$ yang pengaruhnya sangat menonjol jika dibandingkan dengan perlakuan larutan $\mathrm{NaOH}$ yang lain. Namun untuk pengaruh pengekelompokan tidak menunjukan hasil signifikan atau dengan kata lain bahwa proses pengelompokan data tidak memberikan pengaruh terhadap kualitas $\mathrm{pH}$ gelatin kulit domba, artinya hipotesis $\mathrm{H}_{0}$ diterima dan hipotesis $\mathrm{H}_{1}$ ditolak dimana $\mathrm{F}_{\text {hitung }}<\mathrm{F}_{\text {tabel }}(\alpha: 0,05)$ dan $(\alpha: 0,01)$ berikut :

Derajat kejituan dapat dilihat dari hasil koefisien keragaman $(\mathrm{KK})$ dari RAK sebagai

$$
\begin{aligned}
\mathrm{KK} & =\frac{\sqrt{\mathrm{KTG}}}{\overline{\mathrm{y}}} \times 100 \% \\
\mathrm{KK} & =\frac{\sqrt{0.0007}}{5.243} \times 100 \% \\
\mathrm{KK} & =0,51 \%
\end{aligned}
$$

Percobaan dengan perlakuan konsentrasi larutan $\mathrm{NaOH}$ mempunyai derajat kejituan dan keandalan yang kecil, dimana nilai KK berdasarkan RAK adalah 0,51\%. Maka untuk untuk 
melakukan uji lanjut sebaiknya uji Beda Nyata Jujur (BNJ). Jika nilai KK kecil maka uji lanjut yang tepat adalah uji BNJ [7].

\section{Efisiensi RAK terhadap RAL}

Untuk mengetahui efisiensi RAK terdahap RAL harus menggunakan rumus berikut :

Efisiensi RAK terhadap RAL $=\frac{\text { KTG RAL }}{\text { KTG RAL }}$

$$
\begin{aligned}
& =\frac{0.0010}{0.0007} \\
& =1,43
\end{aligned}
$$

Berdasarkan data hasil perhitungan efisiensi RAK terhadap RAL menunjukan angka 1,43 yang berarti terjadi efisiensi RAK 1,43 kali efisiensi RAL dalam menonjolkan pengaruh konsentrasi larutan $\mathrm{NaOH}$ terhadap $\mathrm{pH}$ gelatin kulit domba yang dihasilkan.

\section{Perbandingan RAK dan RAL}

Perbandingan RAK dan RAL pada dasarnya untuk membandingkan semua hasil sumber keragaman dan pengambilan keputusan atau kesimpulan secara spesifik serta mengetahui kelebihan dari RAK dan RAL pada setiap kasus percobaan. Data perbandingan RAK dan RAL disajikan pada tabel 7 sebagai berikut :

Tabel 7. Perbandingan hasil analis sidik ragam menurut RAK dan RAL

\begin{tabular}{llll}
\hline Hasil Analisis Ragam & RAK & & RAL \\
\hline DB Galat & 9 & $<$ & 13 \\
JK Galat & 0.0061 & $<$ & 0.0135 \\
KT Galat & 0.0007 & $<$ & 0.0010 \\
$\mathrm{~F}_{\text {hitung }}$ (perlakuan) & 88.4016 & & 57.485 \\
$\mathrm{~F}_{\text {hitung (kelompok) }}$ & 3.6639 & $>$ & - \\
$\mathrm{F}_{\text {tabel }}$ (perlakuan) & $3.86 ; 6.99$ & $<.41 ; 5.74$ \\
$\mathrm{KK}$ & $0,51 \%$ & $<$ & $0,62 \%$ \\
\hline
\end{tabular}

Berdasarkan tabel 7. dapat dibandingkan perbedaan RAK dan RAL secara keseluruhan, dimana RAK menyebabkan derajat bebas, jumlah kuadrat dan kuadrat tengah galat serta KK lebih kecil, sedangkan $F_{\text {hitung }}$ dan $F_{\text {tabel }}$ lebih besar daripada RAL. Sehingga metode RAK mampu lebih menonjolkan pengaruh perlakuan konsentrasi larutan $\mathrm{NaOH}$ terhadap $\mathrm{pH}$ gelatin kulit domba.

\section{KESIMPULAN}

Berdasarkan hasil Rancangan Acak Lengkap didapatkan $F_{\text {hitung }}>F_{\text {tabel }}(\alpha: 0,05)$ dan $(\alpha: 0,01)$. Sehingga dapat disimpilkan bahwa perlakuan $\mathrm{NaOH}$ sangat mempengaruhi kualitas $\mathrm{pH}$ gelatin kulit domba dan hasil Rancangan Acak Kelompok didapatkan hasil $F_{\text {hitung (perlakuan) }}>F_{\text {tabel (perlakuan) }}$ $(\alpha: 0,05)$ dan $(\alpha: 0,01)$. Sehingga dapat disimpilkan bahwa perlakuan $\mathrm{NaOH}$ sangat mempengaruhi kualitas $\mathrm{pH}$ gelatin kulit domba, namun untuk $\mathrm{F}_{\text {hitung (kelompok) }}<\mathrm{F}_{\text {tabel (kelompok) }(\alpha: 0,05) \text { dan }(\alpha: 0,01)}$ tidak signifikan. Nilai Koefisien Keragaman (KK) untuk RAK dan RAL memiliki persentase yang kecil sehingga harus dilanjutkan dengan uji BNJ. 


\section{DAFTAR PUSTAKA}

[1] Y. W. Gustriza Erda, Tatik Widiharih, "Rancangan Acak Kelompok Tak Lengkap Seimbang Parsial (RAKTLSP)," J. Gaussian, vol. 4, no. 2009, hal. 277-286, 2015.

[2] V. K. Gupta, R. Parsad, dan B. N. Mandal, Significance of Experimental Designs in Agricultural Research, no. August. New Delhi: ICAR-Indian Agricultural Statistics Research Institute, 2015.

[3] B. S. Adinugraha dan T. N. Wijayaningrum, "Rancangan Acak Lengkap dan Rancangan Acak Kelompok Pada Bibit Ikan," in Seminar Nasional Pendidikan, Sains dan Teknologi - Fakultas Matematika dan Ilmu Pengetahuan Alam - Universitas Muhammadiyah Semarang, 2004, hal. 47-56.

[4] M. Hasdar dan Y. D. Rahmawati, "Nilai pH, Titik Leleh dan Viskositas Pada Gelatin Kulit Domba Asal Brebes Yang Dikatalis Berbagai Konsentrasi NaOH,” Parapemikir J. Ilm. Farm., vol. 5, no. 2, hal. 98-102, 2016.

[5] A. A. Gomez dan K. A. Gomez, "Statistical procedures for agricultural research: second Edition," A Wiley-Interscience Publ., vol. 6, hal. 690, 1984.

[6] S. Nugroho, Rancangan Percobaan, Pertama. UNIB Press, 2008.

[7] K. A. Hanafiah, Rancangan Percobaan: Teori Dan Aplikasi, Ketiga. Jakarta: PT Raja Grafindo Persada, 2014.

[8] Paiman, Perancangan Percobaan Untuk Pertanian, Pertama. Yogyakarta: UPY Press, 2015. 